Int. J. Electrochem. Sci., 11 (2016) $4550-4559$

\title{
Biosynthesis of Gold Nanoparticles Using Green Alga Pithophora oedogonia with Their Electrochemical Performance for Determining Carbendazim in Soil
}

\author{
Lei $\mathrm{Li}^{1}$ and Zunju Zhang, ${ }^{2, *}$ \\ ${ }^{1}$ Northeast Petroleum University at Qinghuangdao, No. 550 West of Hebei Rd, Haigang, \\ Qinhuangdao, Hebei, 066004, P.R. China \\ ${ }^{2}$ Environmental Management College of China, No. 8 Jingang Rd, Beidaihe, Qinhuangdao, Hebei, \\ 066402, P.R. China \\ *E-mail: baxiannv1@126.com
}

doi: $10.20964 / 2016.06 .13$

Received: 3 March 2016 / Accepted: 8 April 2016 / Published: 4 May 2016

\begin{abstract}
Biosynthesis nanomaterial have constituted a huge attention recently due to its non-toxic process. In this work, we demonstrated the biosynthesis of Au nanoparticles using green algae Pithophora. oedogonia as reducing agent. The entire synthesis process was rapid and the Au nanoparticles were formed within in $1 \mathrm{~h}$ after the Au salt reacted with algal extract. UV-vis spectroscopy and X-ray photoelectron spectroscopy were confirmed the formation of metallic state of Au. The average size of the biosynthesized $\mathrm{Au}$ nanoparticles was characterized to be $32.06 \mathrm{~nm}$ using scanning electron microscopy and dynamic light scattering machine. The biosynthesized Au nanoparticles were then used for screen printed electrode surface modification and showed an excellent electrocatalytic activity towards determination of carbendazim molecules in soil.
\end{abstract}

Keywords: Biosynthesis; Algae; Electrocatalysis; Sensor; Carbendazim

\section{FULL TEXT}

(C) 2016 The Authors. Published by ESG (www.electrochemsci.org). This article is an open access article distributed under the terms and conditions of the Creative Commons Attribution license (http://creativecommons.org/licenses/by/4.0/). 